\title{
LA FALLIDA REFORMA DEL FEDERALISMO ALEMÁN
}

\author{
IGNACIO GUTIÉRREZ GUTIÉRREZ \\ Profesor Titular de Derecho Constitucional \\ UNED
}

\author{
SUMARIO \\ I. Problemas del federalismo alemán. \\ II. Objetivos de la Comisión. \\ III. Composición y trabajos de la Comisión. \\ IV. Propuestas. \\ V. El horizonte de las reformas: ¿federalis- \\ mo competitivo adaptado a la globaliza- \\ ción?
}

El Bundestag y el Bundesrat, mediante resoluciones adoptadas respectivamente los días 16 y 17 de octubre del año 2003, crearon una comisión conjunta ${ }^{1}$ cuyo objetivo, conforme al artículo segundo de tales resoluciones, era elevar propuestas a las cámaras legislativas orientadas a la modernización del régimen federal de la República Federal de Alemania; si la Comisión considerara necesario reformar la Ley Fundamental, habría de proponer formulaciones concretas.

Las propuestas debían estar elaboradas dentro del año 2004, conforme a la última frase del art. 11 de las resoluciones constitutivas de la Comisión; pero requerían el voto favorable de dos tercios de sus miembros. Como es sabido, el 17 de Diciembre de 2004 los presidentes de la Comisión hubieron de protoco-

1 Kommission von Bundestag und Bundesrat zur Modernisierung der bundesstaatlichen Ordnung, abreviadamente denominada Bundesstaatskommission o Comisión sobre el federalismo. En la página web del Bundesrat (http://www.bundesrat.de/Site/Inhalt/DE/) existe un link que conduce a los diversos documentos producidos en su seno, incluidos los diarios de sesiones. Sobre ellos se apoya fundamentalmente este trabajo. En cualquier caso, muchos datos, y las valoraciones correspondientes, ya se habían ido acumulando a lo largo del año 2004, durante una estancia investigadora en la cátedra del Prof. Dieter Grimm en la Universidad Humboldt de Berlín, financiada la Fundación Alexander von Humboldt. 
lizar la ausencia del consenso exigido. Este fracaso, sin embargo, no hace que pierdan interés los debates y materiales producidos en tal marco, y que en este informe nos limitaremos a resumir ${ }^{2}$. De un lado, la extraordinaria calidad de los asesores que participaron en sus trabajos ${ }^{3}$ convierte los numerosos documentos que produjeron para la Comisión en un excelente punto de partida para el análisis del federalismo alemán. De otro, los debates pusieron de manifiesto que el diagnóstico sobre las dificultades del federalismo en Alemania resulta ampliamente compartido, persiste la necesidad de la reforma y siguen siendo válidas las vías fundamentales trazadas para abordarla. Así lo atestigua el hecho de que múltiples instancias políticas, sociales y económicas propusieran la inmediata reanudación de las negociaciones a partir de los consensos alcanzados; la necesidad de tomar distancia respecto del proceso abortado y el desarrollo entretanto de la vida política alemana no han permitido que esa iniciativa se realizara.

\section{PROBLEMAS DEL FEDERALISMO ALEMÁN}

Tras la Segunda Guerra Mundial, las potencias aliadas de ocupación decidieron consagrar el federalismo como principio estructural de la nueva Alemania; tal determinación estaba ciertamente en consonancia con una arraigada tradición, por más que la cultura política alemana se haya desarrollado en buena medida alentando una centralización que se impusiera a las rémoras tradicionalistas encarnadas, como atestigua la experiencia histórica, en los viejos Estados. El federalismo se convierte así en uno de los principios básicos de la Ley Fundamental, garantizado por la cláusula de irreformabilidad del art. 79 GG. Ahora bien, tal principio está abierto a concreciones diversas, que tampoco resultan contrarias a la Ley Fundamental: en parte eran ya previsibles a partir de su propio texto ${ }^{4}$, en parte han sido incorporadas a él mediante reformas. La valoración crítica de la situación a la que ha terminado llegando el federalismo alemán es compartida, en líneas generales, por todos los integrantes de la Comisión, aunque el acento, especialmente a la hora de establecer las prioridades de la reforma, se ponga en uno y otro aspecto. Pareciera que los equilibrios originalmente previstos por la Ley Fundamental se hubieran pervertido, siendo

2 Sólo ocasionalmente, en la medida en que lo exija la exposición, se esbozarán algunos aspectos del vigente régimen federal alemán; no procede una exposición más detallada, que se puede encontrar, por ejemplo, en las contribuciones de H. J. Vogel ("El régimen federal de la Ley Fundamental") y D. Posser ("Significado del Bundesrat") al Manual de Derecho Constitucional editado por E. Benda, W. Maihofer, H.J. Vogel, K. Hesse y W. Heyde (edición en castellano a cargo de A. López Pina, Madrid/Barcelona: Marcial Pons, 2001-2. ${ }^{a}$ ed.).

3 Ocho son profesores de Derecho Público (Dieter Grimm, Peter Huber, Ferdinand Kirchhof, Hans Meyer, Edzard Schmidt-Jortzig, Hans-Peter Schneider, Rupert Scholz y Joachim Wieland), dos de ciencia política (Arthur Benz y Fritz W. Scharpf) y dos economistas (Stefan Homburg y Rüdiger Pohl).

4 La misma existencia de competencias concurrentes, por ejemplo, abre la tendencia al desplazamiento de las competencias legislativas de los Länder en favor de la Federación. 
sustituidos por un bloqueo que todos reconocen, y que sin embargo nadie quiere superar entretanto no se le garantice en la nueva situación una posición relativa al menos equivalente a la actual.

a) Conforme al texto originario de la Ley Fundamental, las competencias legislativas corresponden a los Länder entretanto la propia Ley Fundamental no disponga otra cosa (art. $70 \mathrm{GG}$ ). Al margen de la relación de competencias exclusivas que se atribuyen a la Federación (art. 73 GG), el ejercicio por ésta de las denominadas competencias concurrentes excluye la legislación de los Länder (art. 72.1 GG); pero está sometido a ciertas condiciones (art. 72.2 GG). También restringen la capacidad legislativa de los Länder la legislación marco (art. 75 GG, sometida igualmente a las condiciones del art. 72.2 GG) y una legislación de principios en muy concretas materias (art. 109.3 GG, y también art. 140 GG en relación con art. 138 de la Constitución de Weimar). En fin, la Federación puede influir sobre políticas que en principio son responsabilidad de los Länder en el ámbito de las llamadas tareas comunitarias (art. 91 a y 91 b GG) y mediante las ayudas financieras (art. 104a 4 GG) que dan lugar a la denominada financiación mixta; porque el principio conforme al cual el titular de la competencia corre con los gastos correspondientes resulta reversible, de modo que la financiación federal de ciertas políticas permite al Bund codeterminar su diseño y su ejecución.

La Federación ha utilizado todas estas atribuciones en términos que, con el transcurso del tiempo, amenazan con anular la capacidad de configuración política a disposición de los Länder. Las disposiciones constitucionales apenan pueden contener el proceso. Por ejemplo, las restricciones para el ejercicio federal de las competencias concurrentes dejan tal margen de apreciación política que el Tribunal Constitucional renuncia inicialmente a controlarlo. Sólo recientemente ha mostrado cierta eficacia el intento de reconducir esta jurisprudencia mediante la reforma constitucional del art. $72.2 \mathrm{GG}$, que en 1994 redacta en términos más precisos las condiciones bajo las cuales la Federación puede asumir las competencias concurrentes. La nueva jurisprudencia constitucional, sin embargo, no tiene como efecto directo el reforzamiento de la posición de los Länder, que siguen necesitando de una ley federal para reasumir el ámbito competencial ocupado por la legislación federal en las materias que ya no requieran de la intervención de la Federación (art. 72.3 GG); simplemente, al constatar que la federación no puede intervenir, por no concurrir las condiciones reforzadas que ahora impone por el art. 72.2 GG, la regulación existente queda petrificada.

En todo ello se insiste desde la perspectiva de los Länder; el Presidente de Baden-Württemberg, Erwin Teufel, señala en la sesión inaugural de la Comisión que en Alemania no existe un problema con el federalismo, sino con el centralismo: se estarían desarrollando de modo excesivo, sin contrapeso alguno, las formas cooperativas orientadas a lograr un equilibrio entre los Länder y a crear condiciones de vida iguales en toda Alemania.

b) Sin embargo, lo cierto es que, como compensación por el recorte de sus competencias legislativas, los Länder han logrado una mayor participación en la 
elaboración de la legislación federal. Inicialmente se preveía que el concurso del Bundesrat sería imprescindible para adoptar leyes federales aproximadamente en un $10 \%$ de los casos; la estimación resultó desde un principio desbordada, pero la cifra supera hoy el 60\%. Ello depende esencialmente de dos factores.

De un lado, el Bundesrat ha apoyado diversas reformas constitucionales con la condición de que incorporaran el incremento de sus derechos de concurso a la legislación federal. Los Presidentes de los Länder ven así satisfecha su vanidad: en lugar del segundo plano que les corresponde como jefes de un gobierno parlamentario en un Land, se ven proyectados a la política nacional, donde además encarnan el papel decisivo que se atribuye al Bundesrat en la legislación federal. Pero ello ocurre a costa de los Parlamentos de los Länder, que pierden competencias legislativas en favor de la Federación y que, sin embargo, carecen de influencia real en las decisiones que los gobiernos de los Länder adoptan luego en el Bundesrat o en la Comisión de Mediación. Al cambiar la primogenitura que se concreta en competencias legislativas por el plato de lentejas que supone el poder del Bundesrat (Scharpf), los Länder ven restringida la posibilidad de desarrollar políticas propias; que bien podrían servir, especialmente a los políticos de la oposición, para poner a prueba, en la realidad y ante la opinión pública, proyectos alternativos a los del Gobierno federal.

El art. 84 GG es el segundo elemento que determina el inesperado peso del Bundesrat: las leyes de la Federación que incorporan disposiciones sobre procedimiento y organización administrativas, en principio competencia de los Länder, necesitan de su aceptación. Que no ha de recaer, como cabía suponer, sólo sobre tales disposiciones administrativas: la jurisprudencia del Tribunal Constitucional alemán sujeta al acuerdo del Bundesrat el conjunto del proyecto; incluso las reformas de tales leyes, aunque no se refieran a los preceptos que determinaron la necesidad de asentimiento del Bundesrat, están sujetas a su acuerdo cuando, por razones sistemáticas, «alteren sustancialmente al significado y alcance de las disposiciones originarias" que impusieron tal requisito. Con ello se concede a este órgano una amplísima posibilidad de intervención en la legislación federal, aunque la responsabilidad última bien pueda corresponder al Gobierno y a la mayoría en el Bundestag, que añaden a las reglas materiales que les compete elaborar disposiciones de las que, al menos conforme al orden constitucional de competencias, bien podrían prescindir.

En definitiva, el Bundesrat tiene en Alemania capacidad para bloquear la mayor parte de las iniciativas legislativas apoyadas por la mayoría del Bundestag que sostiene al Gobierno. Y ese bloqueo no es infrecuente, en particular porque viene siendo habitual que no concuerden las mayorías políticas en el Bundestag y el Bundesrat. Por lo demás, las reglas de decisión en esta Cámara favorecen la decisión negativa: al tener que votar todos los representantes de cada Land en un mismo sentido, las discrepancias entre ellos, frecuentes cuando proceden de gobiernos de coalición, se saldan con la abstención; pero, al exigirse mayoría absoluta para obtener el acuerdo del 
Bundesrat, tales abstenciones equivalen a un rechazo del proyecto remitido por el Bundestag.

El paso siguiente supone remitir la decisión a la bicameral Comisión de Mediación, que decide sobre paquetes legislativos heterogéneos en reuniones a puerta cerrada, mediante acuerdos que se demoran indefinidamente y que resultan a la postre difíciles de explicar. Así se retrasan o bloquean los procesos de decisión, se reducen los resultados a un ineficaz máximo común denominador y se hace imposible determinar quién es responsable último de las decisiones que se adoptan. Desde el doble punto de vista de la democracia, que también exige la asignación clara de responsabilidades, y de la eficacia de las respuestas políticas a los siempre urgentes desafíos del presente, tal situación parece insatisfactoria. Peer Steinbrück (Presidente de Renania del Norte-Westfalia) insiste en ello a partir de la noción anglosajona de "accountability"; pero la constatación es generalizada.

También las facultades atribuidas al Bundesrat por el llamado «artículo sobre Europa" de la Ley Fundamental (art. 23 en la redacción que le fue dada tras la reunificación ${ }^{5}$ ) se percibe como un bloqueo de las posibilidades de acción y decisión de Alemania en el contexto de la Unión Europea. La participación de los Länder, a través del Bundesrat, en la formación de voluntad estatal que debe ser trasladada a las instituciones comunitarias ${ }^{6}$, restringe de modo directo o indirecto la capacidad de maniobra de los representantes de Alemania en el Consejo de la Unión Europea, pues tienen que salvar las rigideces impuestas por el mandato constitucional para llegar a acuerdos con otros Estados miembros de la Unión. El precepto constitucional pretende una mejor salvaguarda de los intereses de los Länder alemanes, que podrían ser desatendidos a causa del amplio margen de maniobra del que suelen gozar los Gobiernos en las instituciones europeas; pero en la práctica perjudica la posibilidad de que Alemania negocie, reaccione y forme alianzas en función de las complejidades de los debates europeos. Dificulta, en definitiva, la defensa de sus intereses generales,

5 Complementado con la Ley de 12 de Marzo de 1993 sobre la colaboración de la Federación y los Länder en asuntos relacionados con la Unión Europea y el acuerdo de 29 de Octubre del mismo año entre el gobierno federal y los gobiernos de los Länder previsto por el $₫ 9$ de dicha Ley.

6 El apartado sexto supone la solución extrema, de hecho apenas utilizada: conforme a dicho precepto, la representación que corresponde a Alemania como miembro de la Unión, cuando sean afectadas competencias legislativas exclusivas de los Länder, debe ser transferida por la Federación a un representante de éstos designado por el Bundesrat, que actuará conjuntamente y de acuerdo con el Gobierno Federal, atendiendo en todo caso a la responsabilidad que corresponde a la República federal en su conjunto. Tal precepto desatiende requisitos fundamentales de funcionamiento eficaz de las relaciones en el marco de la Unión: la continuidad de las representaciones estatales genera experiencia en relación con las materias implicadas y con los procedimientos de negociación y decisión, además de confianza recíproca con los representantes de otros Estados. Pero también en los demás supuestos, en los que el Gobierno debe atender (diferenciadamente) a los intereses de los Länder expresados por el Bundesrat, estas indicaciones, formuladas desde la perspectiva de quien ha de ejecutar administrativamente las normativas adoptadas, pueden alcanzar tal grado de detalle que las convierten en documentos inmanejables en el concreto marco negociador. 
que incluyen los de sus Länder. En la Comisión se llega a decir, con un acuerdo sorprendente, que los daños han sido limitados en la medida en que, pragmáticamente, se han desatendido u obviado las exigencias constitucionales?

Este segundo bloque de problemas, relacionado con la posición adquirida por el Bundesrat en el régimen político alemán, es invocado especialmente por los representantes del Gobierno, que ven dificultada la realización del programa político mayoritariamente apoyado en las elecciones generales, pero también por miembros de la Comisión procedentes del Bundestag que pertenecen a partidos de la oposición.

\section{OBJETIVOS DE LA COMISIÓN}

a) La Comisión asume el reto fundamental de desenredar el nudo gordiano, la maraña organizativa y competencial que hace casi imposible deslindar en Alemania quién resulta en cada caso responsable de una determinada decisión: la Federación o los Länder, el Gobierno apoyado por el Bundestag o el Bundesrat, la mayoría o la oposición con capacidad de bloqueo en esta segunda Cámara, los procesos públicos de decisión democrática o los compromisos secretos adoptados en la Comisión de Mediación. Ello se debe conseguir, de un lado, limitando la influencia de los Länder en la determinación de la política de la Federación, mediante la disminución de los supuestos en los que las Leyes requieren la conformidad del Bundesrat por ejemplo (se insiste) a la mitad. Pero, naturalmente, ello sólo es aceptable para los Länder si, de un lado, se amplían sus competencias legislativas, revirtiendo el proceso mediante el cual la atribución de competencias a la Federación se compensaba mediante el reforzamiento del Bundesrat. En segundo lugar, se debe garantizar a los Länder que la legislación federal que en adelante pueda ser adoptada por la mayoría del Bundestag sin el concurso del Bundesrat no va a interferir en sus competencias. En resumen, podría decirse que se trata de reducir las competencias de los Gobiernos de los Länder en el Bundestag para incrementar las de los Parlamentos de cada Land.

Las resoluciones que dan vida a la Comisión ofrecen una formulación menos directa, pero igualmente inequívoca de estos objetivos: se trata de mejorar la capacidad de acción y decisión de la Federación y de los Länder, atribuir con mayor claridad las responsabilidades políticas, y aumentar la eficacia y la eficiencia del cumplimiento de las tareas públicas. La Comisión debía revisar en particular la atribución de las competencias legislativas a la Federación y a los Länder, las competencias y derechos de concurso de los Länder en los ámbitos de la legislación federal y las relaciones financieras entre la Federación y los Länder (con particular atención a las denominadas tareas comunitarias y a la financiación mixta). Del mismo modo, había de tener en cuenta tanto el

7 Probablemente tal experiencia resulta decisiva a la hora de acordar, en el tramo final de las negociaciones, el mantenimiento del status quo en esta materia. 
desarrollo de la Unión Europea como la situación de la administración local, los dos niveles territoriales complementarios de la ordenación territorial del poder.

Con estas determinaciones queda delimitado también el alcance de la reforma. Así, de haberse abordado la reordenación de los Länder existentes, cuyas disparidades en extensión, población y capacidad económica se consideran a veces disfuncionales, las reticencias de los pequeños Länder y de las ciudades Estado hubieran bloqueado el proceso; sólo la mención de Berlín como capital federal en la Ley Fundamental, con la vista puesta también en su prevista fusión con Brandenburgo, es puesta sobre la mesa de trabajo de la Comisión. La reforma tampoco afecta a los aspectos centrales que determinan las relaciones financieras en el régimen federal; la redistribución de competencias se extiende a la legislación tributaria y a las tareas que la Federación subvenciona en forma de tareas comunitarias o ayudas financieras; pero fuera del debate quedan, por ejemplo, los instrumentos de equilibrio interterritorial y el llamado pacto de solidaridad que beneficia hasta el año 2019 a los Länder incorporados a la República Federal en $1990^{8}$.

b) Aun así, un proyecto tan ambicioso sólo puede ser comprendido si concurren una insatisfacción generalizada y apremiante con la situación existente y una coyuntura particularmente favorable para abordar su reforma.

Las disfunciones persisten desde hace varios años; pero se hacen acuciantes ante las dificultades de la economía alemana en un contexto de cambios globales acelerados, que parecen imponer urgentes reformas económicas y sociales, imposibles sin embargo de tramitar conforme a los procesos decisorios consagrados en el vigente régimen federal. Por eso, la reforma de este régimen federal no se concibe como un cambio de las estructuras constitucionales con significado autónomo, sino muy especialmente al servicio de proyectos políticos específicos. Podría tratarse, en gráfica expresión del Presidente de Baviera Edmund Stoiber, de "la madre de todas las reformas". Una formulación menos pedestre corresponde al ya mencionado Peer Steinbrück, que cita a Goethe: "Das Was bedenke, mehr bedenke Wie"; y añade: "el 'qué', la sustancia, son las leyes materiales, especialmente las reformas que ocupan en estas semanas y estos meses la tarea legislativa del Bundestag y el Bundesrat. El 'cómo' son nuestras instituciones federales, sus competencias y procedimientos (...) Naturalmente debemos reflexionar sobre la sustancia -así interpreto a Goethe-, pero con ello no debemos desatender el camino por el que podemos alcanzar el objetivo. Los retos y las aspiraciones que debe satisfacer el 'cómo', el orden federal, han crecido continuamente en las últimas décadas (...) y se han ido modificando. El federalismo alemán, tal y como hoy se presenta a nuestros ojos, resulta demasiado condicionado, demasiado inflexible, demasiado lento y de-

$8 \mathrm{El} \mathrm{hecho} \mathrm{de} \mathrm{que} \mathrm{la} \mathrm{reforma} \mathrm{sólo} \mathrm{pudiera} \mathrm{afectar} \mathrm{a} \mathrm{cuestiones} \mathrm{financieras} \mathrm{de} \mathrm{segundo} \mathrm{rango}$ seguramente determinó que, en este extremo, los acuerdos alcanzados fueran mínimos: no podían entrar en juego compensaciones realmente significativas para quienes se sintieran perjudicados por alguna propuesta. 
masiado opaco. Temo que no sea adecúe a una Europa ampliada y constituida, y cada vez resulta menos apto para hacer frente a los retos de la intensa competencia que la economía globalizada impone a nuestras regiones".

Tal vinculación de la reforma del federalismo con proyectos específicos promovidos por el Gobierno federal no provocaba, sin embargo, particulares reservas en los partidos de la oposición; al menos en principio?. En primer lugar, porque existe acuerdo entre los grandes partidos sobre la necesidad de un amplio proyecto de reformas sociales y económicas, que en parte ya se había ido poniendo en marcha. En segundo término, el desbloqueo del régimen federal no sólo beneficiaría a las mayorías en el Bundestag, sino que ampliaría igualmente la capacidad de configuración de los Länder, en buena medida gobernados por la oposición, o al menos por coaliciones diferentes de la que sostiene al Canciller. Por último, y quizá sobre todo, las expectativas electorales en el momento de la constitución de la Comisión eran favorables para los democristianos alemanes, que podían confiar en que las facilidades que obtuviera inicialmente el Gobierno de la llamada coalición rojiverde pronto serían igualmente disfrutadas por la coalición CDU-CSU, eventualmente aliada con el liberal $\mathrm{FDP}^{10}$.

\section{COMPOSICIÓN Y TRABAJOS DE LA COMISIÓN}

a) De la Comisión forman parte dieciséis miembros de cada una de las Cámaras y otros tantos suplentes; éstos pueden concurrir a todas las sesiones de la Comisión, pero sólo tienen derecho de propuesta y de voto en caso de ausencia del correspondiente titular. Su nombramiento se regula en las respectivas resoluciones por las que cada una de las Cámaras contribuye a la constitución de la Comisión: los del Bundestag son elegidos por éste a propuesta de los grupos parlamentarios; por su parte, el Gobierno de cada Land designa a un miembro de la Comisión y a su suplente.

El Gobierno designa igualmente cuatro representantes en la Comisión (en calidad de miembros consultores), que participan activamente en sus sesiones y tienen derecho de iniciativa, pero no de voto; puede también designar otros tantos suplentes. Con el mismo estatuto participan en las sesiones de la Comisión seis diputados de los parlamentos de los Länder; sus suplentes pueden participar en todas las sesiones, pero el uso de la palabra y el derecho de iniciativa sólo concurren en caso de ausencia de un miembro titular.

9 Pese a la insensibilidad que ponen de manifiesto la Ministro de Justicia en la sesión inaugural: "A la gente no le importa tanto, al menos por lo que yo aprecio, quién hace qué, sino que lo necesario sea hecho".

10 Precisamente este argumento permite sospechar que pueda haber existido alguna relación entre el descenso de las expectativas electorales democristianas en los últimos meses del año 2004 y el fracaso de la Comisión: habría decaído el interés de la coalición CDU/CSU por desbloquear el procedimiento legislativo en favor del Bundestag, perdiendo la influencia que le otorga la clara mayoría de la que disfruta en el Bundesrat. 
No como miembros de la Comisión, sino en calidad de invitados permanentes, aunque con el mismo estatuto que los miembros consultores elegidos por los parlamentos de los Länder, participan en la Comisión igualmente tres representantes de los Presidium de las federaciones de entes locales, designados por éstas, y sus suplentes.

Finalmente, asesoran a la Comisión doce expertos designados por ella, pero carecen de derecho de iniciativa y de voto.

Todos los nombramientos son revocables, y las vacantes pueden ser cubiertas por iniciativa de los que tuvieron el derecho de propuesta.

b) La Presidencia de la Comisión se ejerce conjuntamente por un miembro del Bundestag y otro del Bundesrat elegidos por la propia Comisión; la propuesta recae respectivamente en Franz Müntefering, presidente del grupo parlamentario del partido socialdemócrata en el Bundestag, que el 21 de marzo del 2004 sería nombrado presidente también del partido tras la renuncia al cargo del Canciller Gerhard Schröder; y en Edmund Stoiber, Presidente de Baviera desde 1993 y de la Unión Social-Cristiana bávara (CSU) desde 1999.

La secretaría se establece por acuerdo entre los Presidentes del Bundestag y del Bundesrat; los costes que genera la Comisión son igualmente soportados por ambas Cámaras; las sesiones se celebran, en principio de forma alternativa, en las sedes del Bundestag y del Bundesrat. El procedimiento se rige, en la medida en que sea aplicable, por el Reglamento del Bundestag. En cuestiones de reglamento y de procedimiento se decide por mayoría de dos tercios de los miembros presentes, con posibilidad de veto por parte de la mayoría de los representantes de cualquiera de las Cámaras.

c) La Comisión celebra su primera sesión el 7 de Noviembre de 2003, con una presentación general de la que se deduce ya un balance bastante ajustado de los retos a los que la Comisión ha de hacer frente. En ella toman la palabra los presidentes de las dos Cámaras legislativas, los de la Comisión y una número significativo se sus miembros. A partir de ese momento se forman dos grupos de trabajo, uno sobre "Competencias legislativas y derechos de concurso de los Länder en la legislación federal" y otro sobre "relaciones financieras". El primero de estos bloques de temas centra los debates de la segunda sesión (28 de Noviembre), de la tercera (12 de diciembre) ${ }^{11}$ y la cuarta (celebrada a puerta cerrada los días 22 y 23 de Enero de 2004 en Postdam). La perspectiva de "Europa", también atribuida a la consideración de este grupo de trabajo, será objeto de la sexta sesión (14 de Mayo de 2004) ${ }^{12}$. Las relaciones financieras son objeto de una audiencia pública el día 11 de Marzo (quinta sesión plenaria de la Comisión) y de una sesión a puerta cerrada el 10 de junio (séptima).

11 Que toma la forma de una audiencia pública en la que los expertos exponen su criterio y se someten a las preguntas de los comisionados.

12 Centrada sobre la eventual reforma del art. 23 de la Ley Fundamental, los problemas competenciales que plantean tanto la incorporación del Derecho comunitario como la atribución de la eventual responsabilidad por incumplimiento del mismo, y la posibilidad de vincular a los Länder a los criterios del denominado Pacto de Estabilidad y Crecimiento. 
Entretanto se constituyen ponencias más reducidas, que el 8 de julio (octava sesión) exponen el estado de sus trabajos, avanzados en muy diferente grado: en algunos extremos se aprecian acuerdos o al menos aproximaciones, en otros sólo las divergencias subsistentes, en algún caso sólo cabe enumerar los temas sometidos a debate ${ }^{13}$. Todos se comprometen, sin embargo, a proseguir los contactos políticos durante el verano, a fin de aportar conclusiones el 30 de septiembre y, a continuación, cerrar de modo progresivo los debates. El 14 de Octubre concluyen las deliberaciones sobre las competencias legislativas y el derecho de concurso de los Länder en una nueva sesión a puerta cerrada, que es la novena de las que celebra la Comisión. Los temas de Europa y de seguridad interior se posponen hasta la sesión del 4 de Noviembre, la décima, que se celebra igualmente a puerta cerrada; en ella se cierran igualmente los debates sobre temas financieros.

Concluidas las minuciosas y documentadas deliberaciones, se hace necesario pasar a la adopción de decisiones; el protagonismo corresponde entonces a los Presidentes de la Comisión, que actuaron durante todo el proceso con la mejor disposición, supieron llegar a acuerdos significativos e incluso, haciendo públicos los últimos avances, lograron ejercer presión sobre quienes continuaban resistiéndose al compromiso. Ya a mediados de Noviembre proponen un primer documento de trabajo sobre los elementos centrales de la reforma. El 13 de Diciembre elaboran un borrador de propuesta, que comprende reformas sustanciales del régimen federal. En aspectos importantes, sin embargo, no consiguen un acuerdo sobre la modificación del status quo; la reforma difícilmente llegará hasta ellos, por más que se anuncie la prosecución de las deliberaciones. Estos asuntos aún disputados son la legislación universitaria y la planificación educativa, la legislación marco medioambiental, la seguridad interior (competencias de la policía federal en materia de lucha antiterrorista y competencias en materia de protección contra catástrofes y de protección civil), la colaboración de los Länder en cuestiones europeas y la responsabilidad ante la Unión Europea.

El consenso entre Stoiber y Müntefering permite pronosticar que, al margen de la calidad del resultado, la Comisión cubrirá formalmente su objetivo: la Ley Fundamental sería revisada. Sin embargo, la reunión de los Presidentes de

13 Tales ponencias se refieren, respectivamente, 1 . al art. 84, los derechos de los Länder a apartarse de la legislación federal en ciertas materias y Europa; 2 . competencias legislativas en materia de función pública, incluidas retribuciones y previsión social, seguridad interior y derecho de reunión; 3. educación y cultura, que comprende la educación superior, la construcción de facultades universitarias, el apoyo a la formación, la formación profesional al margen del sistema escolar, la promoción de la investigación científica, la promoción del arte y la cultura y la planificación educativa; 4. competencias legislativas en materia de medio ambiente y protección de los consumidores; 5. posibles competencias legislativas con significado regional; 6. temas financieros. Queda al margen de esa sesión el grupo que analiza la capitalidad de Berlín, aunque existe un acuerdo generalizado (que se concreta en Septiembre) acerca de la conveniencia de que tal circunstancia sea reconocida en la Ley Fundamental, con el efecto de que encuentre respaldo constitucional el apoyo financiero de la Federación a la ciudad para que pueda soportar los costes derivados de su peculiar status. 
los Länder del día 15 y su encuentro con el Canciller Schröder, al día siguiente, incrementan la presión: las nuevas demandas de los Länder no son atendidas, en los extremos aún pendientes resulta imposible cerrar acuerdo alguno. La undécima y última sesión de la Comisión, convocada a puerta cerrada para el día 17 de diciembre de 2004 en la sede del Bundestag, tenía como objetivo adoptar las propuestas para reformar la Ley Fundamental, así como eventualmente otras leyes; del mismo modo, se pretendía aprobar un texto de presentación y un resumen que atendiera a los aspectos centrales de la reforma. De ella salen los Presidentes de la Comisión confirmando la impresión que había comenzado a difundirse durante el día anterior, por la mañana en la reunión de los grupos parlamentarios en el Bundestag y por la tarde en la reunión final entre Stoiber y Müntefering: constatando que el acuerdo no había sido posible.

d) Está generalizada la impresión de que el fracaso se debió a discrepancias a la hora de distribuir las competencias que afectan a la educación. Los Länder habían atribuido a esta cuestión, desde el inicio de los trabajos de la Comisión, un valor simbólico: en un ámbito esencial para desarrollar políticas que doten de perfil singular a los diferentes Länder, sus competencias les habrían sido expropiadas; de modo que cualquier reforma debe comenzar por desandar ese camino.

El traslado a la Federación de las competencias en materia de educación se apoya, en primer lugar, en las denominadas "tareas comunitarias", que incluyen no sólo la construcción y reforma de Facultades, incluidas las clínicas universitarias (art. 91.a 1.1. GG), sino también, en virtud de acuerdos entre la Federación y los Länder, la colaboración en la planificación educativa y en la promoción de institutos y proyectos de investigación de alcance suprarregional (art. 91 b GG). Por lo demás, la Ley marco interpreta los principios generales de la regulación universitaria (art. 75.1.1a GG) en términos extraordinariamente amplios; en expresión del antiguo Presidente Federal Roman Herzog, "el marco se ha extendido tanto que ya no deja sitio para el cuadron. El reequilibrio que pretenden los Länder se puede valorar atendiendo a sus consecuencias financieras: aspiran a controlar, en adelante, el 85\% del correspondiente presupuesto. Incluyen en sus peticiones la regulación relativa a la calidad de enseñanza, el acceso a la Universidad y la certificación de títulos académicos, sin que la Federación parezca dispuesta a ceder en estos extremos; desde el SPD, por ejemplo, se rechaza que la planificación educativa y la calidad de la enseñanza superior puedan quedar completamente sustraídas a la influencia de la Federación, justo cuando la competitividad internacional de las economías estatales descansa crecientemente sobre la formación y la educación, mientras que los célebres estudios de Pisa dejan a Alemania en un lugar que se estima poco alentador.

Las razones del fracaso, sin embargo, son con seguridad más complejas. La Comisión trabaja, especialmente en sus últimas fases, con el tácito compromiso de que se podrán proponer los cambios sobre los que exista acuerdo, dejando al margen los aspectos disputados, en los que se conservaría el status quo; las divergencias en un solo tema, por importantes que fueran, no podrían impedir el éxito del proyecto. Tal expectativa no podía verificarse sino bajo ciertas 
condiciones: entre los diferentes aspectos de la reforma existía una íntima conexión, de modo que la falta de acuerdo en un extremo se proyectaba necesariamente sobre el conjunto de los equilibrios alcanzados. Ahora bien, es difícil de aceptar que las discrepancias sobre una cuestión específica desencadenaran, por mucha que fuera su radicalidad, el fracaso de todo el proyecto: es éste en su conjunto el que resulta tan endeble que, a la postre, se hace políticamente insostenible. La cuestión educativa pudo constituirse en pretexto idóneo para que unos y otros se aferraran a un status quo quizá perverso, pero a fin de cuentas equilibrado.

Todo indica que el conflicto final estaba planteado en términos federales, aunque nadie niegue el papel complementario que han podido desempeñar las alineaciones partidarias. La Federación, representada por los grupos parlamentarios de la mayoría y de la oposición en el Bundestag y con la intervención (sin derecho de voto) del Gobierno federal, apenas podrá actuar de modo coordinado. Enfrente, los Länder llegaron a acuerdos significativos entre ellos, formularon con claridad sus propuestas y supieron mantenerlas con firmeza. Hubo incluso representantes de Länder gobernados por los partidos en el Gobierno federal que no dudaron en imputar el fracaso de las negociaciones a la rigidez mostrada por éste; la actitud intransigente que se atribuye a algunos Presidentes de Länder gobernados por la democracia cristiana tampoco deriva forzosamente de instrucciones procedentes de la dirección central del partido, sino que se corresponde sea con perspectivas sobre el federalismo determinadas por el ejercicio de las propias responsabilidades, sea con aspiraciones e intereses personales. En tal situación negociadora, se ha planteado que el fracaso pudiera obedecer a estrategias conscientes de unos (especialmente de ciertos políticos de la oposición asentados en determinados Länder, que pretendían conservar el poder del que gozan en el Bundesrat y así, mediatamente, su presencia en la política federal) o a cálculos deficientes de otros (por ejemplo del Gobierno, que se habría arriesgado en sus juegos tácticos, siendo descubierto por los Länder antes de alcanzar plenamente sus objetivos). Pero todas estas hipótesis resultan de imposible verificación. Lo único cierto es que, concluidos los plazos, los Presidentes de la Comisión fueron incapaces de forzar un acuerdo.

Más que dilucidar las responsabilidades políticas, sin embargo, interesa comprobar en qué medida las reglas que institucionalizan la Comisión dificultan objetivamente el logro de sus objetivos. Como hemos señalado, los acuerdos exigen una mayoría de dos tercios de los miembros de la Comisión, lo que fuerza a orientar los debates hacia soluciones de compromiso. Tales consensos debían cruzar las diferencias no sólo entre gobierno y oposición, sino también entre Bundestag y Bundesrat, y asimismo entre los muy diferentes Länder que forman parte de Alemania: grandes y pequeños, con economía próspera o débil, integrantes de la República Federal desde sus orígenes o sólo tras la reunificación de 1990. Ante tal complejidad de relaciones, todos los participantes son conscientes de que un acuerdo resulta imposible si se pretende un equilibrio general entre todas las partes, como si se tratara de un juego sobre múltiples 
mesas, en todas las cuales debiera alcanzarse la suma cero. Pero esa tendencia es inevitable cuando la reforma se encomienda a los propios implicados en los actuales equilibrios, cuyo primer objetivo es mantener su propia posición de fuerza. Apenas cabía confiar en que la reforma del régimen federal fuera emprendida con éxito por quienes protagonizan su bloqueo; los actores políticos no supieron diferenciar, conforme a la exigencia de Dieter Grimm, la actitud conveniente para emprender reformas constitucionales de la que usualmente encarnan en la vida política cotidiana.

\section{PROPUESTAS}

El principio general que orienta los trabajos de la Comisión es, como se ha visto, fácilmente comprensible. Sin embargo, desde un principio señala el Presidente de Sajonia-Anhalt Wolfgang Böhmer que los acuerdos en los fines generales y las buenas intenciones apenas encubren las dificultades que surgen al descender a lo concreto.

a) Quizá convenga comenzar exponiendo el debate en torno al art. 84 GG. Como hemos señalado, tal precepto sujeta a la conformidad del Bundesrat las leyes federales que contienen reglas sobre su ejecución administrativa, en principio competencia de los Länder; justamente esta invasión del ámbito competencial de los Länder explica la exigencia constitucional de aceptación por parte del Bundesrat. La jurisprudencia del Tribunal Constitucional ha extendido la competencia del Bundesrat al conjunto del proyecto legislativo, y por ello se propuso limitar la reforma a una nueva formulación del precepto que eliminara este efecto. Tal sugerencia, sin embargo, ya había sido sometida a prueba en la realidad, sin haber dado los frutos esperados; pues, en el fondo, se trataría de consagrar constitucionalmente la división de los proyectos legislativos en dos partes diferenciadas: una material, cuya adopción no dependería de la conformidad del Bundesrat, y otra con los contenidos que éste debe asumir. Este intento no había resultado eficaz en el pasado, y la Comisión tampoco le prestó ahora mayor atención.

La solución más simple consistiría en privar a la Federación de la posibilidad de incluir disposiciones sobre la organización y el procedimiento de ejecución en las leyes que adopta en virtud de títulos competenciales materiales. Pero ello tropieza con dos tipos de objeciones. De un lado, la tendencia burocrática a formular proyectos normativos exhaustivos y unitarios descansa en el temor, no siempre infundado, al bloqueo de las decisiones materiales por demora, inadecuación o divergencia excesiva en las disposiciones organizativas y procedimentales que cada Land ha de adoptar para su ejecución; en algunos Länder faltaría incluso la capacidad técnica para asumir tal tarea. De otra parte, en ciertos supuestos no resultaría posible separar con claridad los aspectos materiales de los procedimentales u organizativos; como señala Dieter Grimm, ante problemas de acelerado desarrollo y gran complejidad técnica, que además cada vez adquieren mayor importancia, apenas es posible concebir solu- 
ciones materiales estables: son suplidas por reglas de organización y procedimiento que pretenden, ante todo, encauzar las innovaciones que se van planteando.

Por ello se postula mantener la competencia de la Federación para emanar normas de organización y procedimiento, pero convirtiendo tales normas federales en derecho meramente supletorio: los Länder podrían adoptar normas que se apartaran, en mayor o menor medida, de las incluidas en la ley federal. De este modo decaería la necesidad de que el Bundesrat aprobara la ley en la que aparecieran tales disposiciones, dado que no suponen una verdadera injerencia en las facultades de los Länder: a éstos siempre les cabrá adoptar sus propias normas. De otra parte, se salvaría en lo esencial la unidad de regulación, pues se da por supuesto que, en la mayor parte de los casos, sólo algunos Länder se apartarían de la legislación federal, y sólo para regular aspectos singulares. Cabría incluso suponer que, si una de esas normas evidencia su idoneidad, sería asumida por los demás Länder o por la propia ley federal, recuperándose así la unidad de regulación. También se preservaría de este modo, en fin, el interés de ciertos Länder por no verse obligados a regular por sí mismos todos esos aspectos.

Ciertos asesores plantean en la Comisión la conveniencia de que se prevean supuestos y condiciones en los que la normativa de carácter organizativo y procedimental pudiera tener carácter no de derecho dispositivo para los Länder, sino de ius cogens. En tales casos, en los que la unidad de regulación fuera requerida por circunstancias similares a las que permiten a la Federación asumir las competencias concurrentes, la aprobación del Bundesrat seguiría siendo requerida.

Todo este esquema es recogido en la propuesta final de Stoiber y Müntefering, que dejan pendiente la inclusión de una cláusula que exceptúe, en garantía del derecho de los Länder a apartarse de la legislación federal, la regla general de prevalencia del derecho federal consagrada en el art. 31 GG; no dejan de resultar significativas las resistencias que encuentra en Alemania la quiebra de un principio dogmático tan firmemente asentado como éste.

Como prueba de la conexión existente entre los diversos temas abordados por la Comisión y de las complejidades que laten en sus compromisos, puede señalarse cómo la reforma del art. 84 GG se intenta modular incluyendo la necesidad de acuerdo del Bundesrat en ciertas leyes con significativas repercusiones económicas sobre los Länder. Porque la garantía de la soberanía organizativa y procedimental incorporada al art. 84 GG se utilizaba también, en la práctica, para controlar los efectos financieros de las leyes federales sobre los Länder llamados a su ejecución. Ahora, cuando las leyes federales ya no llevan aparejadas decisiones organizativas vinculantes y dejan márgenes suficientes para que los Länder puedan ejecutarlas con criterios propios, la responsabilidad sobre el gasto les corresponde; pero sigue siendo cierto que puede tratarse de leyes con costes económicos para ellos, y que ya no podrán someter a control en el Bundesrat; pues, conforme a la regulación vigente, el acuerdo de éste sólo se requiere cuando una ley federal determina prestaciones económicas que co- 
rren, al menos en una cuarta parte, a cargo de los Länder. La nueva formulación propuesta el 13 de Diciembre extiende tal derecho a todos los supuestos en los que las leyes federales obligan a los Länder a otorgar a terceros prestaciones económicas o materiales con valor económico; una declaración complementaria precisa, entre otros extremos, que en tal redacción se comprenden también las prestaciones de servicios que conlleven costes elevados para los Länder o, en general, los supuestos en los que la ley federal no atribuya a los Länder un marco significativo para determinar con autonomía el alcance de la prestación del servicio.

Con todo ello, la propuesta del 13 de diciembre estima que el acuerdo del Bundesrat seguiría siendo necesario en un 35 o 40\% de las leyes federales.

b) Las mencionadas propuestas ejemplifican las diversas técnicas mediante las cuales los Länder pueden recuperar sus competencias legislativas. La más sencilla consiste en excluir las correspondientes materias del listado de las competencias concurrentes o del ámbito en el que la Federación puede dictar leyes marco; de este modo, siempre que no se establezca que la competencia debe mantenerse (ya como exclusiva) en manos de la Federación, pasaría a la competencia de los Länder, ganando éstos en capacidad de configuración normativa.

También se planteó la creación de un nuevo tipo de competencia de la Federación, en la cual se reconocería a los Länder el derecho a apartarse de las normas federales. La Federación podría regular exhaustivamente la materia, sin sujetarse a condiciones materiales como las exigidas para adoptar la legislación concurrente ni someterse a la necesidad de aprobación por el Bundesrat; los Länder podrían apartarse de la legislación federal de modo total o parcial, amplicando su margen de maniobra sin estar por ello obligados a legislar. Los defensores de esta nueva modalidad competencial no creen que con ella se incurra en el riesgo de una excesiva diversificación legislativa en Alemania; en palabras de Erwin Teufel, «todo lo que debe ser regulado unitariamente, sólo puede ser regulado unitariamente de verdad, hoy en día, a escala europea, y así ocurre de hecho. Tal marco europeo es naturalmente vinculante también para los Länder". Estas posibilidades de apartarse de la legislación federal son en ocasiones reducidas a simples cláusulas legales de opting-out, que permiten bajo ciertos límites y con ciertos controles la introducción de regulaciones experimentales en los Länder. Podría pensarse que ello apenas supone un verdadero cambio en la distribución constitucional de competencias, pero Wolfgang Böhmer considera que la propuesta podría resultar interesante en la medida en que se definieran condiciones precisas para que una región pudiera apartarse de la regulación general y formular sus propias iniciativas; el ejemplo que utiliza es la legislación laboral: le parece interesante pensar en lo que ocurriría si, "en regiones con un índice de paro que supere ampliamente la media federal - digamos en un 50\%—, ciertas disposiciones dejaran de ser aplicables de modo provisional".

Ahora bien, la introducción de esta nueva modalidad competencial exigiría un pormenorizado acuerdo acerca del alcance y los límites del derecho de los 
Länder en cada materia concreta. La Comisión terminó prefiriendo la estrategia, aparentemente más simple, de reasignar las competencias a una de las partes en litigio, en su caso tras dividirlas en sectores materiales diferenciados.

En efecto, una ampliación de las competencias de los Länder que les permita configurar su propias opciones políticas exige una clara delimitación material con las que corresponden a la Federación, para evitar solapamientos que en la práctica menoscaban la autonomía de los Länder. Por ello, la sustitución de la legislación concurrente por leyes marco o leyes de principio, como vía para ampliar las competencias de los Länder, es descartada en Alemania: la experiencia avala las reservas expresadas por Roman Herzog, que ya se reprodujeron más arriba. En las propuestas finales de Stoiber y Müntefering no desaparece por entero la legislación marco existente debido a las discrepancias sobre la asignación de ciertas competencias ahí recogidas, no porque la figura reciba adhesiones particulares; lo mismo ocurre con las tareas comunitarias.

c) Estas nuevas formas de delimitar las competencias de la Federación y los Länder deben ser puestas en relación con las correspondientes materias: en ese momento comienzan las verdaderas dificultades. Al efecto podría distinguirse entre la fijación de un principio general de atribución y su concreción en competencias específicas. Las disputas en materia de educación, a las que ya se ha hecho referencia, ilustran sin embargo que no se está sólo ante cuestiones de principio, sino también ante asignaciones de poder y de recursos públicos.

Erwin Teufel propone como regla general el principio de subsidiariedad, del que deriva la presunción de competencia a favor de los Länder. Tal principio se habría invertido en la práctica, y se trataría de hacerlo de nuevo reconocible en la realidad constitucional. En Alemania las diferencias entre los Länder habrían llegado a ser percibidas, al decir de Wolfgang Böhmer, no como enriquecimiento, sino más bien como agravio comparativo: «finalmente habremos de responder a la pregunta acerca de cuánta diversidad osamos asumir en Alemania». Frente a ellos, Wolfgang Bosbach, diputado de la CDU en el Bundestag, se pregunta qué le queda a éste tras someterse a la presión de Europa y de los Länder, y responde: "tanta diversidad federal como sea posible, pero también tanta unidad como resulte necesaria.. Y la ministro socialdemócrata Brigitte Zypries añade: "no puede tratarse de proponer la diversidad por el mero gusto de la diversidad. Debemos definir, más bien, dónde son necesarios en Alemania estándares unitarios y de dónde no debe retirarse el legislador federal, que garantiza la unidad".

Descendiendo a algunas materias significativas, debe mencionarse, en primer lugar, la función pública; desde la primera sesión solicitan los Länder, al menos, el derecho de apartarse de las reglas federales en lo que se refiere a las retribuciones de sus funcionarios. Las propuestas finales suprimen casi por completo la competencia concurrente o de legislación marco que correspondía a la Federación en tal ámbito: sólo retiene la regulación, bajo reserva de acuerdo con el Bundesrat, de los derechos y deberes que corresponden a los funcionarios (el alcance de la competencia se precisa de nuevo en un texto complementario); promoción, retribuciones y previsión social pasan a corresponder a los Länder. 
También en este caso se pone de manifiesto la conexión entre los objetivos inmediatos de la Comisión y las reformas políticas cuya realización debe quedar expedita mediante sus trabajos. El debate sobre la atribución de las competencias en materia de función pública se vincula a la necesidad de actualizar la interpretación de la garantía institucional de la misma contenida en el art. 33.5 GG. A fin de que las competencias ahora reasignadas puedan ser utilizadas efectivamente en el sentido pretendido, el acuerdo final se extiende a la modificación de tal precepto, en términos que impiden que tal garantía se continúe entendiendo como una perpetuación del status quo: los principios tradicionales de la función pública quedan así abiertos a la configuración y el desarrollo del legislador competente.

La propuesta final también excluye del ámbito de las competencias concurrentes o de la legislación marco al menos otras trece materias en beneficio de los Länder: desde la regulación del derecho de reunión o de la prensa, pasando por la ejecución penal, hasta las ferias, exposiciones, mercados y locales de juegos, o el cierre de comercios. Otros ejemplos de menor relieve han permitido desdeñar la relevancia efectiva de estas asignaciones competenciales, especialmente en los casos en que constituyen fragmentos de antiguas competencias concurrentes: desatendiendo los objetivos de la Comisión, no se eliminaría de este modo la necesidad de coordinar el ejercicio de competencias, que recaen, ahora aún más que antes, sobre materias objetivamente entrelazadas.

En sentido contrario, se convierten en competencias exclusivas de la Federación ciertas competencias concurrentes, por ejemplo en materia de regulación de las armas, materiales explosivos y energía nuclear, así como la legislación marco sobre empadronamiento y permisos de residencia. Del mismo modo se transfieren a la competencia exclusiva de la Federación, conforme a la propuesta formulada por los Presidentes de la Comisión el 13 de Diciembre, la protección del patrimonio cultural para evitar su expatriación. Más importante es el hecho de que, en muchas de las materias que siguen dentro del listado de competencias concurrentes, dejan de ser aplicables las condiciones materiales que restringían el ejercicio de la competencia por parte de la Federación; se vuelve así, en ellas, a la situación anterior a 1994, cuando el ejercicio de las competencias concurrentes dependía sólo de la discrecionalidad del legislador federal.

Desatar el nudo del federalismo cooperativo resulta especialmente difícil cuando se abordan las relaciones financieras. Existe un cierto acuerdo en la Comisión acerca de los problemas derivados de las denominadas tareas comunitarias, que exigen acuerdos multilaterales de todos los Länder con la Federación, y que por ello plantean numerosos problemas de responsabilidad y de gestión. Su supresión, siempre que se asignen a los Länder los recursos correspondientes, les concedería mayor libertad en la asignación del gasto. Ahora bien, la fórmula para tal asignación de recursos resulta disputada entre los propios Länder. El reforzamiento de su autonomía fiscal podría ser la primera opción; pero los Länder económicamente más débiles temen que les depare 
una insuficiencia presupuestaria, al menos por comparación con otros Länder que pueden atraer recursos precisamente mediante la rebaja de sus impuestos. Por eso la vista se dirige hacia otro género de compensaciones económicas, que en cualquier caso no deberían llevar aparejadas tantas complejidades organizativas, ni intromisiones severas en la gestión de los Länder: las llamadas "ayudas financieras", que se apoyan en acuerdos bilaterales y no incorpora controles tan intensos de la Federación.

El tantas veces citado acuerdo del 13 de Diciembre, dejando al margen algunos aspectos de menor relieve, se limita a suprimir una de las tareas comunitarias (la construcción y renovación de Facultades Universitarias, y ni siquiera por completo): simplemente, no existe acuerdo sobre cuantía, criterios y plazos de la correspondiente compensación. Las ayudas financieras también entrecruzan responsabilidades, y en esa medida estaban destinadas a ser revisadas en la propia Comisión. El acuerdo aquí se extiende, de un lado, a la conservación de las ayudas financieras existentes hasta 2012 y al establecimiento de una compensación financiera que se fijará en ese momento y se aplicará hasta 2019, aunque ya sin adscribir a fines específicos. Pero también se revisa el instrumento mismo: en adelante sólo pueden afectar a materias que no sean de competencia exclusiva de los Länder (a fin de que la Federación no intente influir en el ejercicio de tales competencias a cambio de dotaciones financieras específicas), se debe establecer por tiempo limitado y someter a ciertos controles (que pretenden también evitar que los acuerdos bilaterales entre la Federación y un Land levantes suspicacias de los demás Länder).

Finalmente, se llega a un acuerdo sobre el régimen de responsabilidad financiera por los incumplimientos del Pacto de Estabilidad de la Unión Europea (repartida entre Federación y Länder, y fijada por Ley en una proporción de 65 y $35 \%$; de la cuantía correspondiente a los Länder, el $65 \%$ se distribuirá en función de su participación en el déficit, el $35 \%$ restante atendiendo al criterio, que se estima solidario, del número de habitantes).

d) Descartada unánimemente la sustitución del Bundesrat, como Cámara de los Estados, por un Senado de elección directa conforme al modelo norteamericano, sugerida por el Presidente del Tribunal Constitucional Hans Jürgen Papier, tampoco se profundizó en algunas propuestas de reforma referidas al funcionamiento del Bundesrat que podrían haber contribuido a los fines perseguidos por la Comisión: por ejemplo, la sustitución de la mayoría absoluta por la mayoría relativa, la prohibición de que un Land se abstenga en las votaciones o la posibilidad de que los votos correspondientes a un Land se emitan en sentidos diferentes.

\section{EL HORIZONTE DE LAS REFORMAS: ¿FEDERALISMO COMPETITIVO ADAPTADO A LA GLOBALIZACIÓN?}

La Comisión, en resumen, tiene como objetivo transformar el vigente $f e$ deralismo cooperativo, orientado hacia la participación de los diversos niveles 
territoriales en la adopción de decisiones unitarias, en un nuevo federalismo que atribuya a los diferentes niveles territoriales una amplia capacidad de configuración autónoma. Ese nuevo modelo estructural tendría, naturalmente, una diferente referencia material. La idea del federalismo competitivo late desde la primera sesión plenaria de la Comisión; en el mismo momento de constituirse, el Presidente del Bundesrat propone como objetivo que los Länder puedan competir abiertamente por desarrollar mejores políticas; la idea es asumida incluso por Franz Müntefering, aunque bajo la reserva de la garantía de la solidaridad. Con ello comienzan las dificultades de concreción.

Erwin Teufel, con no poca radicalidad, reduce la garantía de la solidaridad a proveer una distribución justa de las oportunidades para los ciudadanos de cualquier Land, sin necesidad de nivelar todas las circunstancias y condiciones vitales; y, aún así, advierte de que no es el Estado central, pese a configurar un sistema jurídico y económico unitario, quien proporciona verdaderamente la igualdad de oportunidades. El federalismo competitivo es defendido consecuentemente por Ernst Burgbacher, diputado del Partido liberal (FPD) en el Bundestag, para quien la equivalencia o unidad de condiciones de vida, mencionada por dos veces en la Ley Fundamental, no es proclamada como un fin del Estado: «debemos despedirnos de la falsa ideología de la nivelación, a fin de cuentas dañosa para todos (...) el federalismo no significa igualarlo todo, sino lo contrario: autonomía de los Länder, competencia y garantía de la diversidad cultural, social, económica y política». Las ventajas del federalismo competitivo se aprecian también en la competitividad exterior: el gigante económico alemán, cuya democracia federal tanto dificulta los cambios, estaría peor dotado para la competencia internacional que otros pequeños Estados europeos, capaces de innovar y corregir con agilidad; tal ventaja comparativa debería ser ganada en Alemania para los Länder.

Ahora bien, los Länder tienen muy diferentes condiciones de partida en tamaño, población y potencia económica; no debe extrañar, pues, que la alusión a una competencia entre ellos levante no pocos recelos: bien puede estimularse una competencia por la mayor calidad de las políticas que garantizan las tareas públicas, pero no cabe basarla, por ejemplo, en la disminución de los impuestos y el ofrecimiento de otras ventajas a las empresas que se asienten en un determinado territorio. Para que los Länder tengan capacidad para configurar sus propias políticas, cada Land debe disponer de medios suficientes para llevar a cabo sus proyectos; el incremento de las competencias de los Länder, por tanto, debe hacerse sin quebrar las estructuras de solidaridad.

La respuesta del liberal Ernst Burgbacher resulta rotunda: «los Länder que a largo plazo son incapaces de competir, son a largo plazo también incapaces de sobrevivir"; lo cual le lleva a defender la reordenación del territorio; algo que, como se ha visto, quedaba fuera de las tareas de la Comisión. Ello pone de manifiesto, desde una nueva perspectiva, las dificultades con las que tropezaba una reforma como la aquí planeada. En la medida en que se pretende encontrar una articulación novedosa para uno de los principios estructurales que identifican un orden constitucional, como el federalismo en Alemania, se hace ne- 
cesario innovar también los demás postulados, en este caso el del Estado social. La Comisión estaba así abocada a sobrepasar sus propios límites. Ahora bien, no sólo por razones dogmático-jurídicas más o menos refinadas, sino también por razones histórico-políticas e institucionales, el poder de reforma no es capaz de ponerse en el lugar del poder constituyente. Quizá por ello la proyectada reforma resultó fallida. 